\title{
A STUDY ON THE POSSIBILITIES OF REDUCING THE SAFETY STOCK BY MODELLING AND ANALYSING THE STOCK REPLENISHMENT PROCESS
}

\begin{abstract}
The paper describes the course of study on the stock replenishment process in a production company. The study has proven that improvement in the information exchange between the Producer and the Supplier of raw materials brings business-related benefits. The example shown concerns the reduction of stock of a selected material, replenished as part of a system based on the reorder point. The automation of activities related to information processing has shortened the duration of certain stages of stock replenishment, which, on the basis of basic dependencies within the replenishment system, has allowed reducing the safety stock kept to ensure production continuity in conditions of uncertain demand. It was possible to introduce changes in the replenishment process (both on the Producer's and the Supplier's part) owing to a profound analysis of the process itself. The example presented applies the BPMN 2.0 standard and the iGrafx tool.

Keywords: stock, safety stock, process, BPMN, optimisation, process analysis JEL: O330
\end{abstract}

\section{Introduction}

Despite the development of alternative concepts of managing flows of goods, stock management under conditions of random changes of demand still remains an important issue. The task gets even more challenging when, in addition to random demand variability, there are also changes (often of a random nature) of the replenishment lead time. It is also important to properly identify all time components of the total replenishment lead time. In many cases it is the purchaser, not the supplier, that is responsible for some of them (order preparation, 
transportation, reception of goods). All these subprocesses have their own "times" and time deviations.

Thus, it is important to develop a model for calculation of basic parameters controlling a given replenishments system (e.g. the reorder point model), where all the identified lead time components (mean values and standard deviations) are included. In order to make use of the model most efficiently one has to look for all possibilities leading to potential process improvements by reducing some of the lead time components and their variabilities. Business Process Modelling was used for the purpose of the research reported in this paper.

The main research goal was to investigate what impact the application of business process modelling may have on the stock replenishment process and one of its key performance indicators - the safety stock level. The research was conducted in an industrial environment.

\section{Methodology and theory}

The considerations presented below refer to stock replenishment based on the reorder point (Figure 1), where the stock replenishment cycle should commence at the moment of achieving (or dropping below) the so-called reorder point (level) B.

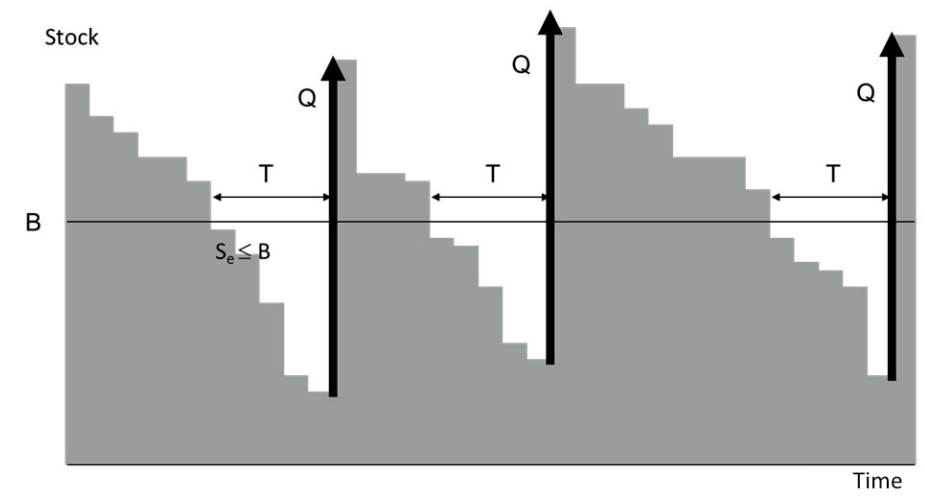

Figure 1. General stock replenishment rules in a system based on reorder point Source: (own elaboration)

In general, the reorder point $B$ may be calculated as follows:

$$
B=\bar{D} \cdot \bar{T}+\sum \overline{x_{i}}+\sqrt{S s_{D}^{2}+S s_{T}^{2}+\sum S s_{x i}^{2}}
$$

In the foregoing formula:

$\bar{D}$ - the average demand in a specific unit of time;

$\bar{T}$ - the mean time of the stock replenishment cycle;

$\bar{x}_{i}$ - the mean values of other factors, related to:

- shortages in the quantity or quality of a delivery; 
- placing orders when the economic stock level $S_{e}$ is significantly lower than level $B$, which, consequently, is related to:

- increased demand in a nominal replenishment cycle, resulting from the actual stock control cycle or the order placing cycle ${ }^{1}$;

- with the nature of demand distribution.

$S s_{D}$ - safety stock resulting from random demand variability:

$$
S s_{D}=\omega_{D}(\alpha S L) \cdot \sigma_{D} \cdot \sqrt{\bar{T}},
$$

where $\omega D(\alpha S L)$ is a safety coefficient corresponding to the adopted service levelthe probability to serve demand in a stock replenishment cycle (Tempelmeier, 2000), for the distribution to which demand applies. It is the standard distribution that usually applies to fast-rotating goods, while it is Poisson's distribution or exponential distribution that applies to slow-rotating goods.

$S s_{T}$ - safety stock resulting from the replenishment cycle time variability:

$$
S s_{T}=\omega_{T}(\alpha S L) \cdot \bar{D} \cdot \sigma_{T},
$$

where $\omega \mathrm{T}(\alpha S L)$ is a safety coefficient corresponding to the adopted service level (the probability to serve demand in a stock replenishment cycle), for the distribution to which the replenishment cycle time applies - in practice, it is not standard distribution but, for example, triangular distribution.

$S s_{x i}$-safety stock resulting from other above listed factors. This part of the safety stock may generally be presented as:

$$
S s_{x}=\omega_{x}(\alpha S L) \cdot \sigma_{x}
$$

where $\omega x(\alpha S L)$ is a safety coefficient corresponding to the adopted service level (the probability to serve demand in a stock replenishment cycle), for the distribution to which the analysed factor applies. It may be standard distribution, but in certain situations a different distribution (e.g. rectangular) may apply (Krzyżaniak, 2015, 2017).

The constituents of the above listed safety stock depend on factors that may be minimised or even eliminated as a result of process analyses.

The main area for potential changes discussed in the present article is the shortening of the stock replenishment cycle time and its variability. Attention should be drawn to the fact that the cycle replenishment duration is a sum of the number of partial stages.

Most of them are the supplier's responsibilities, except for a few, where the responsibility rests with the ordering party. Figure 2 shows an example of such a structure of time $(\mathrm{T})$.

A process analysis was conducted by the authors to verify the impact of the proposed solutions. Process maps, created on the basis of process interviews, were made to ensure the proper quality and readability. The maps were prepared in accordance

1 For example, placing orders at a specific time of day (e.g. in the evening) requires taking into account the expected demand volume in the period from meeting the order conditions $\left(\mathrm{S}_{\mathrm{e}} \leq \mathrm{B}\right)$ to the actual commencement of the stock replenishment cycle. Failure to meet this organisational condition may, in certain situations, result in lower availability of service. 
with the BPMN 2.0. standard - currently the most popular tool for describing business and production processes (Briol, 2010). The maps were later complemented with lead times of individual activities, waiting times between activities, the number of employees involved in the process and schedules of operation to ensure the proper quality and readability. Process models were developed as a result. The models underwent simulations with the use of specialist software (iGrafx) (Ragin-Skorecka, Nowak, 2016).

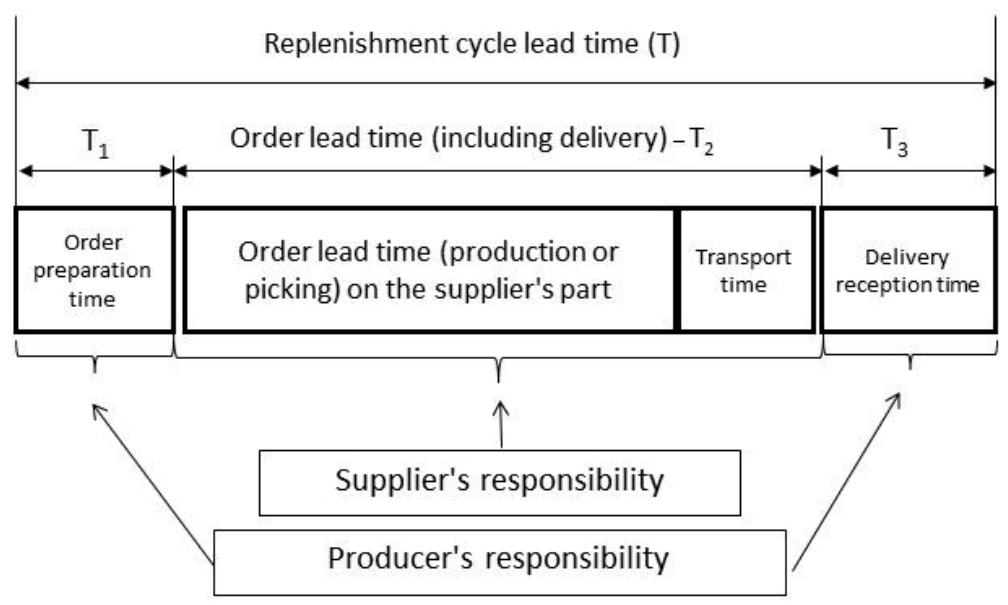

Figure 2. Structure of stock replenishment cycle time (T) for the discussed example Source: (own elaboration)

\section{Results and discussion}

The example assumes that direct transport to the Producer's headquarters is the Supplier's responsibility. The total stock replenishment cycle time (T) is the sum:

$$
T=T_{1}+T_{2}+T_{3}
$$

where:

$T_{1}$ - the time spent on preparing and releasing the order;

$T_{2}$ - the time required for the supplier to complete the order (including delivery);

$\mathrm{T}_{3}$ - the time spent on delivery reception (unloading, inspection in terms of quantity and quality, transport to the warehouse and making an entry on the delivery reception in the IT system).

Considering the processes of order preparation and delivery reception (i.e. the issues for which the producer is responsible), it should be noted that they form a set of operations carried out simultaneously, which have separate lead times (including possible deviations), which is the subject of the process analysis described below. 
The adopted assumptions allow presenting the safety stock as follows:

$$
S S=\sqrt{\omega_{D}(\alpha S L) \cdot \sigma_{D}^{2} \cdot\left(\bar{T}_{1}+\bar{T}_{2}+\bar{T}_{3}\right)+\bar{D} \cdot\left\{\sum_{i=1}^{i=3}\left[\omega_{T_{i}}(\alpha S L)\right]^{2} \cdot \sigma_{T_{i}}^{2}\right\}},
$$

where:

$\bar{D}, \sigma_{D}$ - the average demand and its standard deviation in a specific unit of time; $\bar{T}_{1,2,3}, \sigma_{T_{1,23}}$ the mean times $T_{1}, T_{2}$ and $T_{3}$, according to the formula (5), including their standard deviations;

$\omega_{D}(\alpha S L)$ - safety coefficient corresponding to the service level, for the observed demand distribution;

$\omega_{T_{i}}(\alpha S L)$ - safety coefficients corresponding to an adopted service level, for observed distribution of times $T_{1}, T_{2}$ and $T_{3}$.

It was initially assumed that, from the Producer's perspective, a process analysis should, above all, cover times $T_{1}$ and $T_{3}$, both with reference to the mean value and the standard deviation, as well as, in certain situations, the features characteristic for the distribution frequency of these times. On the other hand, at the stage of implementing improvements shown by the process analysis, time savings were found in $T_{2}$ (the time spent by the Supplier on formal services related to the order), as well. The savings are a result of the information exchange automation achieved due to the integration of IT systems. $T_{3}$ remains unchanged and is not taken into consideration as a source of possible improvements in the present publication. The potential for improved efficiency was determined by comparing two models of stock replenishment processes: the current process (AS IS), presenting the current course of executing orders for raw materials necessary to maintain current production, and the target model (TO BE), providing a new stock replenishment method.

It should be borne in mind that, both for the AS IS and TO BE models, the positive course of executing the researched process only was assumed - the appropriate business roles (Decision-Maker and Manager) always approve the order and the dispatch of goods.

On the basis of the information obtained from warehouse or production employees, an employee responsible for the purchase of raw materials prepares the order (activity: order preparation), which is then verified and approved by a Decision-Maker (activity: order acceptance). The order is sent by the employee responsible for the purchase of raw materials to the Supplier (activity: order placement). The Supplier's Customer Service Department analyses the order (activity: order analysis) and passes it to the manager for review and acceptance (activity: acceptance). The next activity is the picking and release of goods (activities: picking and release) in compliance with the Delivery Note document. The goods (raw material to be used in production) supplied together with the Delivery Note are received by the Producer's target warehouse, which marks the end of the analysed process - the current stock is replenished.

The process model presented below (Figure 3 ) displays a potential for optimisation - the activities which may be eliminated or the duration of which may be shortened by introducing certain improvements, presented on the target process model (Ragin-Skorecka, Nowak, 2017). 
The target process model (TO BE) presented in Figure 4 shows an improved method of ordering raw materials required for current production.

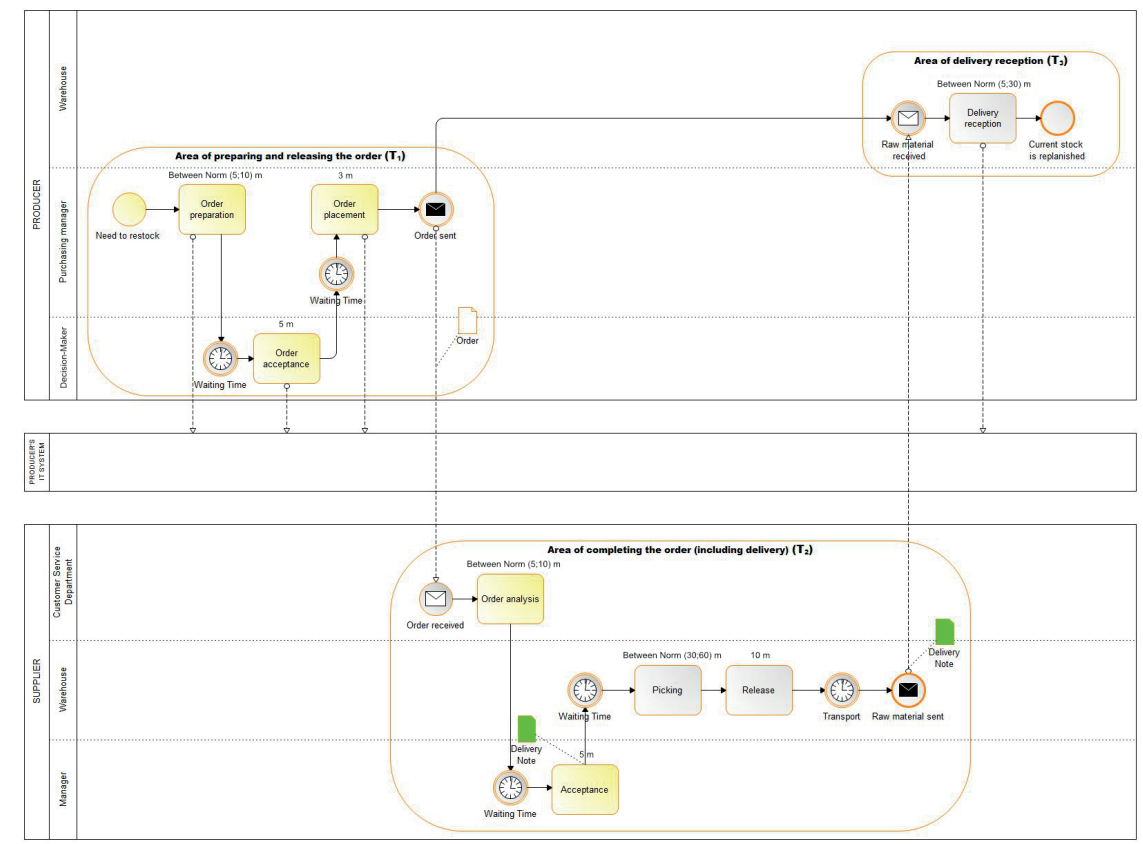

Figure 3. Stock replenishment process map, current status - AS IS

Source: (own elaboration based on own research conducted by the Institute of Logistics and Warehousing, Software used: iGrafx Process 2011 for Enterprise Modelling)

Course of the target process (TO BE):

Due to the automation of activities related to information processing when stock drops to a level at which information urging the Producer to replenish the stock is sent, the Producer's IT system initiates an order directly in the Supplier's IT system. The integration is supported by a data bus (Integrator) serving as a medium for exchanging messages between them. The data bus should operate based on EDM (Enterprise Data Management) or ETL (Extract, Transform and Load) solutions (Christodoulou, Scherer, 2016). The Supplier's system generates a Delivery Note document and orders the picking directly in the warehouse. At the same time, it sends an Order Confirmation to the Producer's IT system. Then, similarly as in the case of the AS IS model, goods are picked and released, and finally received by the Producer.

The volume of orders which are subject to such automation should remain within the limits set out in framework agreements concluded between the Producer and the Supplier. The basis of such agreements may be the data concerning the planned order volume, delivery times and delivery frequencies. Appropriate planning of the terms of framework cooperation is crucial because individual orders will be executed automatically without the need of their approval by decision makers representing the Producer or the Supplier. 
The following assumptions were adopted for the current process (AS IS):

- the number of orders per day - 1 order/day;

- the amount of resources as part of individual business roles -1 resource in each business role;

- the time of work: 8 hours/day, 5 days/week, 22 days/month;

- the process observation time -1 year.

$\bar{D}=71, \sigma_{D}=20$

$T_{1}=255.53[\mathrm{~min}] T_{2}=607.56[\mathrm{~min}] T_{3}=22.68[\mathrm{~min}]$

$\sigma T_{1}=0.85[\mathrm{~min}] \sigma T_{2}=5.1[\mathrm{~min}] \sigma T_{3}=2.5[\mathrm{~min}]$

$\omega_{D}(\alpha S L)=1.64$

$\omega_{T_{i}}(\alpha S L)=1.64$

The following assumptions were adopted for the target process (TO BE):

- the number of orders per day - 1 order/day;

- the amount of resources as part of individual business roles -1 resource in each business role;

- the time of work: 8 hours/day, 5 days/week, 22 days/month;

- the process observation time -1 year.

$\bar{D}=71, \sigma_{D}=20$

$T_{1}=0.0[\mathrm{~min}] T_{2}=355.02[\mathrm{~min}] T_{3}=22.68[\mathrm{~min}]$

$\sigma T_{1}=0.0[\mathrm{~min}] \sigma T_{2}=4.99[\mathrm{~min}] \sigma T_{3}=2.5[\mathrm{~min}]$

$\omega_{D}(\alpha S L)=1.64$

$\omega_{T_{i}}(\alpha S L)=1.64$

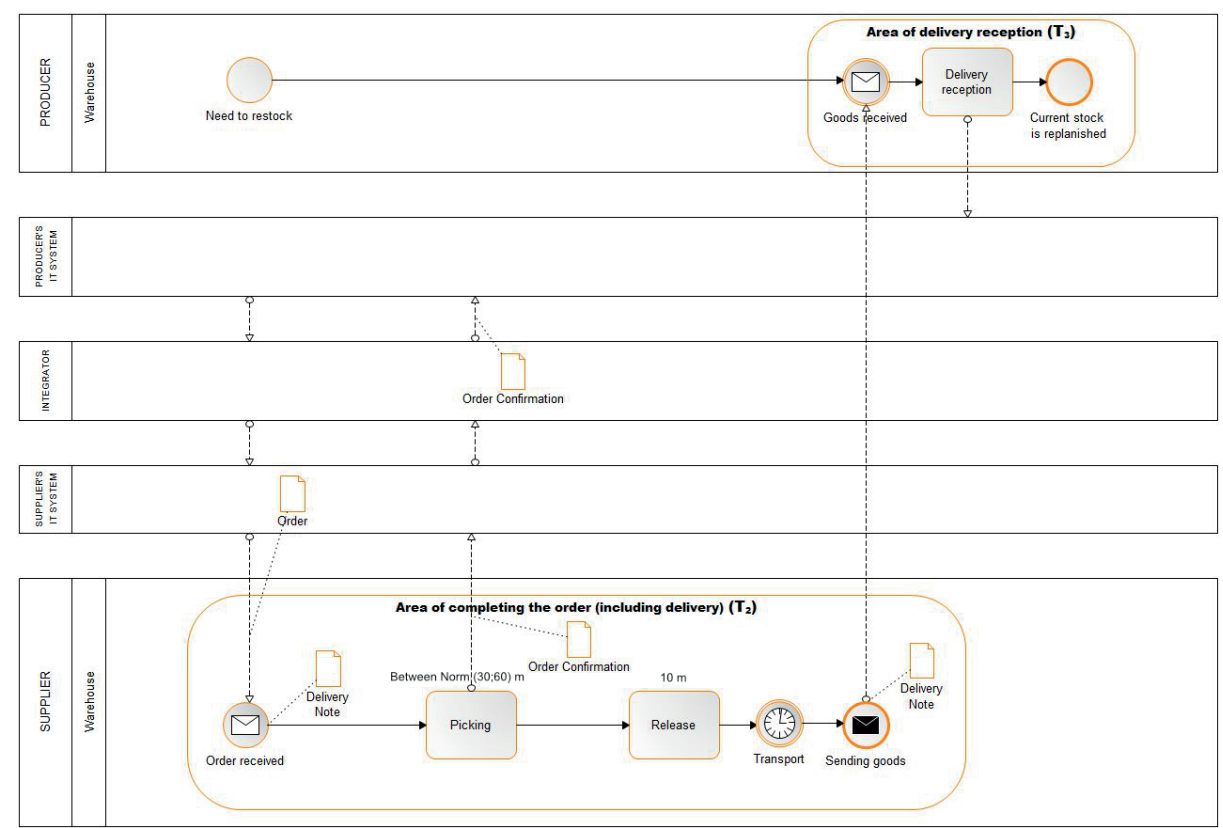

Figure 4. Stock replenishment process map, target status - TO BE

Source: (own elaboration based on own research conducted by the Institute of Logistics and Warehousing, Software used: iGrafx Process 2011 for Enterprise Modelling) 
Results of comparative process simulations for AS IS and TO BE models:

With the purpose of comparing the efficiency of both processes, the simulation results were compared, focusing on the mean service time and the mean use of resources, which were considered key indicators for studying the efficiency of changes in the process (see Table 1).

Table 1. The degree to which resources were used for the execution of tasks assigned to individual business roles in analysed processes

\begin{tabular}{|l|c|c|}
\hline \multicolumn{1}{|c|}{ Business roles } & AS IS & TO BE \\
\hline Stock/Producer/ Purchasing manager & $2.18 \%$ & $0 \%$ \\
\hline Stock/Producer/Decision-Maker & $3.11 \%$ & $0 \%$ \\
\hline Stock/ Supplier/Customer Service & $4.69 \%$ & $0 \%$ \\
\hline Stock/Supplier/Manager & $3.11 \%$ & $0 \%$ \\
\hline Stock/Supplier/Warehouse & $34.19 \%$ & $34.33 \%$ \\
\hline Stock/Producer/Warehouse & $14.10 \%$ & $14.15 \%$ \\
\hline
\end{tabular}

Source: (own elaboration based on own research conducted by the Institute of Logistics and Warehousing)

Use of resources - part of work (in \%), in which a resource (business role) is involved in a specific process (Figure 5).

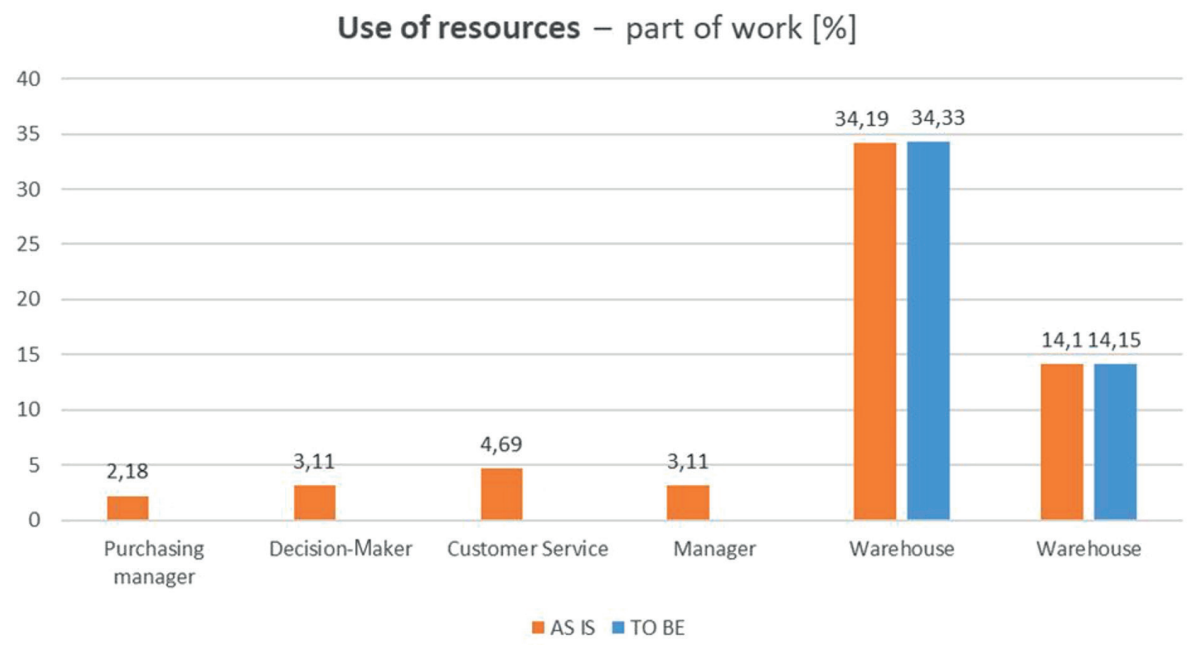

Figure 5. A graphic illustration of the degree to which resources were used for the execution of tasks assigned to individual business roles in analysed processes

Source: (own elaboration based on own research conducted by the Institute of Logistics and Warehousing) 
Mean service time $=T$ - mean time necessary to serve one instance of stock replenishment (Figure 6).

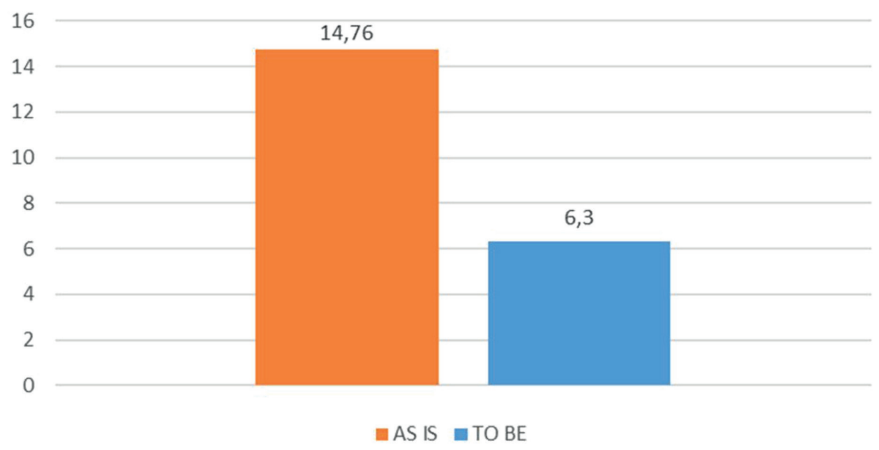

Figure 6. Mean service time in hours

Source: (own elaboration based on research conducted by the Institute of Logistics and Warehousing)

\section{Conclusions}

The operational result of the change was the shortening of the complete stock replenishment process lead time from almost 15 hours to approximately 6 hours. It is therefore possible to perform full stock replenishment on one shift. Furthermore, the operational availability of business roles responsible for accepting orders (decision-maker, manager) and roles handling the formal service of orders (purchasing manager, customer service representative) was increased for other processes carried out by enterprises. It was possible to achieve by reducing their activities in the analysed stock replenishment process.



Figure 7. Structure of safety stock

Source: (own elaboration based on own research conducted by the Institute of Logistics and Warehousing) 
Stock maintained to ensure production continuity (safety stock) will also be significantly reduced (by 31\%) (Figure 8). It is a measurable economic effect of the change, which has directly influenced the decrease in the costs of maintaining the stock of raw materials to be used in production. The initial safety stock (1033 pcs) may be divided into stock securing the flow of raw materials (713 pcs) and the stock securing information flow, which accompanies the stock replenishment process (321 pcs) (Figure 7) - following the automation of the information flow between the producer and the supplier, this part of the stock does not need to be kept.



Figure 8. Projected change in safety stock, in \%, after target model (TO BE) implementation Source: (own elaboration based on own research conducted by the Institute of Logistics and Warehousing)

\section{References}

Briol, P. (2010), BPMN 2.0 Distilled, Lulu.com, Raleigh.

Christodoulou, S., Scherer, R. (2016), eWork and eBusiness in Architecture, Engineering and Construction, ECPPM 2016, CRC Press, Boca Raton.

Krzyżaniak, S. (2015), Model of the Impact of Parameters Controlling Replenishment in the BS (Min-Max) Continuous Review System on the Actual Inventory Availability. LogForum, 11. Krzyżaniak, S. (2017), Klasyczne systemy odnawiania zapasów. In: Fertsch, M. (Ed.), Elementy inżynierii logistycznej, Instytut Logistyki i Magazynowania, Poznań.

Ragin-Skorecka, K., Nowak, F. (2016), Information Is the Key in Optimization of Transport Processes. Information Systems in Management, 5(2), pp. 227-236.

Ragin-Skorecka, K., Nowak, F. (2017), Analiza procesowa jako narzędzie do usprawnienia działalności organizacji. Studia i Prace WNEiZ US, 48(2), pp. 77-88.

Shapiro, R., White, S., Bock, C. (2011), BPMN 2.0 Handbook Second Edition: Methods Concepts, Case Studies and Standards in Business Process Modeling Notation, Future Strategies Inc., USA.

Tempelmeier, H. (2000), Inventory Service-Levels in the Customer Supply Chain. OR Spectrum, 22(3), pp. 361-380.

\section{Corresponding author}

Filip Nowak can be contacted at: Filip.Nowak@ilim.poznan.pl 